\title{
PREPARATION OF ACYCLOVIR-NICOTINAMIDE COCRYSTAL BY SOLVENT EVAPORATION TECHNIQUE WITH VARIATION OF SOLVENT
}

\author{
ROISAH NAWATILA ${ }^{1}$, AGNES NUNIEK W ${ }^{2}$, SISWANDONO SISWODIHARDJO ${ }^{3}$, DWI SETYAWAN ${ }^{1 *}$ \\ ${ }^{1}$ Department of Pharmaceutics, Faculty of Pharmacy, Airlangga University, Dharmawangsa Dalam - 60286, Indonesia. ${ }^{2}$ Department of \\ Pharmaceutics, Faculty of Pharmacy, Surabaya University, Raya Kalirungkut - 60293, Indonesia. ${ }^{3}$ Department of Medicinal Chemistry, \\ Faculty of Pharmacy, Airlangga University, Dharmawangsa Dalam - 60286, Indonesia. Email: dwisetyawan-90@ff.unair.ac.id
}

Received: 13 November 2016, Revised and Accepted: 01 December 2016

ABSTRACT

Objective: This research aims to prepare cocrystal of acyclovir (ACV)-nicotinamide (NCT) by solvent evaporation with a variation of solvent (ethanol, glacial acetic acid, and $\mathrm{HCl} 0.1 \mathrm{~N}$ ) to improve the bioavailability of ACV as an antiviral drug.

Methods: Cocrystal were developed by solvent evaporation with 1:1 molar fraction, using variation of solvent such as ethanol, glacial acetic acid, and $\mathrm{HCl}$ 0.1 N. Further, the prepared ACV-NCT cocrystal were characterized for differential scanning calorimetry (DSC), powder X-ray diffraction (PXRD), Fourier transform infrared spectroscopy (FT-IR), scanning electron microscope (SEM), and in vitro dissolution.

Results: DSC thermogram showed that ACV-NCT cocrystal in ethanol and glacial acetic acid exhibited new endothermic peak at $221.16^{\circ} \mathrm{C}$ and $216.40^{\circ} \mathrm{C}$, whereas no peaks were found for $\mathrm{HCl} 0.1 \mathrm{~N}$. PXRD diffractogram showed that ACV-NCT cocrystal in ethanol exhibited new diffraction peaks at $2 \theta 5.9^{\circ} ; 9.2^{\circ}$; dan $13.3^{\circ}$, whereas no peaks were found for glacial acetic acid and $\mathrm{HCl} 0.1 \mathrm{~N}$. FT-IR characterization of ACV-NCT cocrystal in ethanol showed disappearance of transmission peaks at $3373 / \mathrm{cm}$ indicating the loss of NH bands of NCT. Furthermore, $\mathrm{C}=0$ of ACV and NCT were observed at $1693 / \mathrm{cm}$, and 1666/cm indicated a formation of hydrogen bonding between ACV and NCT. SEM micrographs showed that cocrystals have a different shape compared to ACV and NCT. DE ${ }_{15}$ showed that there was a significant increase of ACV-NCT cocrystal dissolution rate in ethanol compared to the physical mixture and ACV.

Conclusion: The study concludes that ACV-NCT cocrystal in ethanol were successfully formed and the dissolution rate of ACV can increase significantly $(\alpha=0.05)$.

Keywords: Cocrystallization, Solvent, Acyclovir, Nicotinamide, Solvent evaporation.

(C) 2017 The Authors. Published by Innovare Academic Sciences Pvt Ltd. This is an open access article under the CC BY license (http://creativecommons. org/licenses/by/4. 0/) DOI: http://dx.doi.org/10.22159/ajpcr.2017.v10i3.16149

\section{INTRODUCTION}

Acyclovir (ACV) is one of the most commonly used antiviral drugs because of its selectivity and low toxicity. It is primarily used for the treatment of herpes simplex virus Type 1 (HSV-1) and Type 2 (HSV-2) and varicella-zoster virus. However, it has absorption problems due to its poor solubility in water (about $0.2 \%$ at $25^{\circ} \mathrm{C}$ ). This factor negatively influences its oral bioavailability, which is approximately $15-20 \%$ [1]. ACV belongs to the Class IV drugs, according to the Biopharmaceutics Classification System, which has low solubility and low permeability [2]. Poor solubility and/or permeability of active pharmaceutical ingredients (APIs) are the main factors to restrict the bioavailability of APIs during drug discovery and development [3].

Many approaches such as solid dispersion, complex inclusion, prodrug, salts, and solvats have been investigated to improve the solubility and bioavailability. In recent years, modification such as the use of pharmaceutical cocrystals has also been investigated extensively [4]. The defines of cocrystal are homogeneous crystalline materials with structure constituted of multicomponent (generally in a stoichiometry ratio) among which one or more components and are obtains through the establishment of strong hydrogen bonds or van der Waals interactions $[5,6]$. Cocrystal basically includes two components that are the API and the former [7]. For most pharmaceutical cocrystal structures, hydrogen bonds take an important role in directing intermolecular recognition between an API and a coformer molecule [8].
Nicotinamide (NCT) is widely used as cocrystal formers. NCT as vitamin $B$ derivative is often used because it is very safe for the use in humans. The formation of cocrystals generally involves functional groups such as amides, carboxylic acids, and alcohols. NCT has an active amide group with a high electronegativity as results of the $\mathrm{N}$ atom silent pairing that led to a strong intermolecular hydrogen bond, which is required for the formation of cocrystals [9]. For instance, the formation of cocrystals that are composed of ibuprofen-NCT [10] and carbamazepin-NCT [11] have been proved to improve the solubility of the APIs.

Methods that have been used to prepare cocrystals include solvent evaporation grinding, slurring, and ultrasonication [5,7]. Solvent evaporation is commonly used for the preparation of cocrystals. In this technique, both drug substance and coformer are dissolved in a common solvent and allowed to slow evaporation of a solvent. The technique works on the principle of the formulation of hydrogen bond in favorable drug substance and a complementary coformer [6].

The presence of a solvent in the crystallization process causes a lowering the activation energy barrier for the rearrangement of the solute molecules into a crystalline structure $[12,13]$. Ethanol and glacial acetic acid are commonly used in chemical industry and included in the classification of class 3 solvent in Q3C guideline [14]. According to USP, ACV and NCT have freely soluble in $\mathrm{HCl}$ [15].

Based on the above studies, the present studies were carried out to prepare cocrystal system composed of ACV and NCT by solvent 
evaporation with ethanol, glacial acetic acid, and $\mathrm{HCl} 0.1 \mathrm{~N}$ to increase the solubility of ACV. Physicochemical characterization was performed by differential scanning calorimetry (DSC), powder X-ray diffraction (PXRD), Fourier transform infrared spectroscopy (FT-IR) spectroscopy, scanning electron microscope (SEM), and also in vitro dissolution.

\section{METHODS}

\section{Materials}

ACV and NCT were purchased from Sigma-Aldrich ${ }^{\circledR}$, China. Ethanol was purchased from Emsure ${ }^{\circledR}$, Merck KGaA, Germany. $\mathrm{HCl}$ was purchased from Smart-Lab ${ }^{\circledast}$, PT. Smart Lab Indonesia. Glacial acetic acid was purchased from Mallinckrodt $\mathrm{AR}^{\circledR}$, France. Aquadest was purchased from PT. Widatra Bhakti, Indonesia.

\section{Methods}

Preparation of phase diagram of binary system

ACV and NCT were sifted and weighed to obtain particle size in a similar range. The obtained physical mixtures were obtained by simply mixing ACV with NCT at different \%w/w as follows: (9:1), (8:2), (7:3), (6:4), (5:5), (4:6), (3:7), (2:8), (1:9), and (0:10), respectively. The mixtures were gently mixed in a mortar. The melting point of physical mixtures of ACV-NCT was determined by DSC. Endothermic peak was plotted against the molar fraction of the mixture to obtain the phase diagram of ACV-NCT.

\section{Preparation of ACV-NCT physical mixture}

ACV and NCT (equimolar) carefully weighed, $500.0 \mathrm{mg}$ and $271.1 \mathrm{mg}$, respectively. Both powders were homogeneously mixed in a mortar

\section{Preparation of cocrystal using solvent evaporation technique with ethanol}

ACV and NCT (equimolar) carefully weighed as much as $100.0 \mathrm{mg}$ and $54.2 \mathrm{mg}$, respectively. Each compound was dissolved in ethanol separately. ACV was dissolved in approximately $500 \mathrm{ml}$ of ethanol to form a clear solution. NCT was dissolved in approximately $5 \mathrm{ml}$ of ethanol. The two solutions were mixed and stirred for a few minutes. Equimolar solution of both components was evaporated at room temperature for $48 \mathrm{hrs}$. The obtained cocrystal solids were stored in a desiccator under vacuum.

Preparation of cocrystal using solvent evaporation technique with glacial acetic acid

ACV and NCT (equimolar) carefully weighed as much as $1.0 \mathrm{~g}$ and $542.2 \mathrm{~g}$, respectively. Each compound was dissolved in glacial acetic acid separately. ACV was dissolved in approximately $170 \mathrm{ml}$ of glacial acetic acid to form a clear solution. NCT was dissolved in approximately $30 \mathrm{ml}$ of glacial acetic acid. The two solutions were mixed and stirred for a few minutes. An equimolar solution of both components was evaporated at room temperature for $48 \mathrm{hrs}$. The obtained cocrystal solids were stored in a desiccator under vacuum.

Preparation of cocrystal using solvent evaporation technique with $\mathrm{HCl} 0.1 \mathrm{~N}$

$\mathrm{ACV}$ and NCT (equimolar) carefully weighed as much as $1.0 \mathrm{~g}$ and $542.2 \mathrm{~g}$, respectively. Each compound was dissolved in $\mathrm{HCl} 0.1 \mathrm{~N}$ separately. ACV was dissolved in approximately $150 \mathrm{ml}$ of $\mathrm{HCl} 0.1 \mathrm{~N}$ to form a clear solution. NCT was dissolved in approximately $10 \mathrm{ml}$ of $\mathrm{HCl} 0.1 \mathrm{~N}$. The two solutions were mixed and stirred for a few minutes. Equimolar solution of both components was evaporated at room temperature for 8 days. The obtained cocrystal solids were stored in a desiccator under vacuum.

\section{Characterization using DSC}

DSC (DSC, Mettler Toledo, US) was used to analyze the thermal properties. A certain amount of samples, that is, 5-7 mg samples were placed in a sealed aluminum pan. The analysis was performed in a temperature range of $30-300^{\circ} \mathrm{C}$ with a heating rate of $5^{\circ} \mathrm{C} /$ minute.

\section{Characterization using PXRD}

PXRD (Phillips X'Pert diffractometer) analysis was performed at room temperature. The condition of measurement was set as follows: $\mathrm{Cu}$ metal target, $\mathrm{K} \alpha$ filter, voltage of $40 \mathrm{kV}, 15-30 \mathrm{~mA}$. The analysis was performed on the range of $2 \theta$ of $5-40^{\circ}$. Sample was placed on the sample holder and flatted to prevent particle orientation during preparation.

\section{Characterization using FT-IR}

Approximately $1 \% \mathrm{w} / \mathrm{w}$ dispersion of sample powder in potassium bromide $(\mathrm{KBr})$ was prepared by mixing the sample powder with $\mathrm{KBr}$. The infrared spectrum was obtained using infrared spectrophotometer (Perkin-Elmer Instrument, Jasco FT-IR/5300) in wavelength range of $400-4000 / \mathrm{cm}$

\section{Characterization using SEM}

The sample was placed on the sample holder and coated with gold aluminum with a thickness of $10 \mathrm{~nm}$. The sample was then observed at various magnification using SEM instrument (Jeol-JSM-6360LA, Japan) with voltage was set at $20 \mathrm{kV}$ and $12 \mathrm{~mA}$.

\section{In vitro dissolution}

The in vitro dissolution studies of prepared ACV-NCT cocrystal were carried out using USP Type II (paddle) dissolution test apparatus. Cocrystal containing equivalent to $100 \mathrm{mg}$ of ACV were introduced into $900 \mathrm{ml}$ dissolution medium of phosphate buffer $\mathrm{pH} 6.8$ for 45 minutes at $37 \pm 0.5^{\circ} \mathrm{C}$ at a rotation speed of $50 \mathrm{rpm}$. A volume of $5 \mathrm{ml}$ of the aliquots was withdrawn through a filter $(0.45 \mu)$ at the regular interval of $5,10,15,20,30,45$ minutes and replaced with an equal volume of fresh phosphate buffer $\mathrm{pH}$ 6.8. The samples were analyzed with simulant equation at $252.04 \mathrm{~nm}$ and $262.07 \mathrm{~nm}$ for ACV content using a UV spectrophotometer. The ACV release experiments were carried out in three replicate.

\section{RESULTS AND DISCUSSION}

\section{Analysis of phase diagram of binary system}

The phase diagram of ACV-NCT mixture was made using different $\% w / w$ (i.e., 10:0, 9:1, 8:2, 7:3, 6:4, 5:5, 4:6, 3:7, 2:8, 1:9, 0:10)\%. The results show that when a physical mixture of molar ratio $1: 1$ is heated, all of component NCT and part of component ACV melt at the metastable eutectic temperature, forming cocrystal which then melts at $191.94-231.83^{\circ} \mathrm{C}[16]$. The molar ratio of 5:5 showed the optimal melting point of forming a cocrystal as shown in Fig. 1.

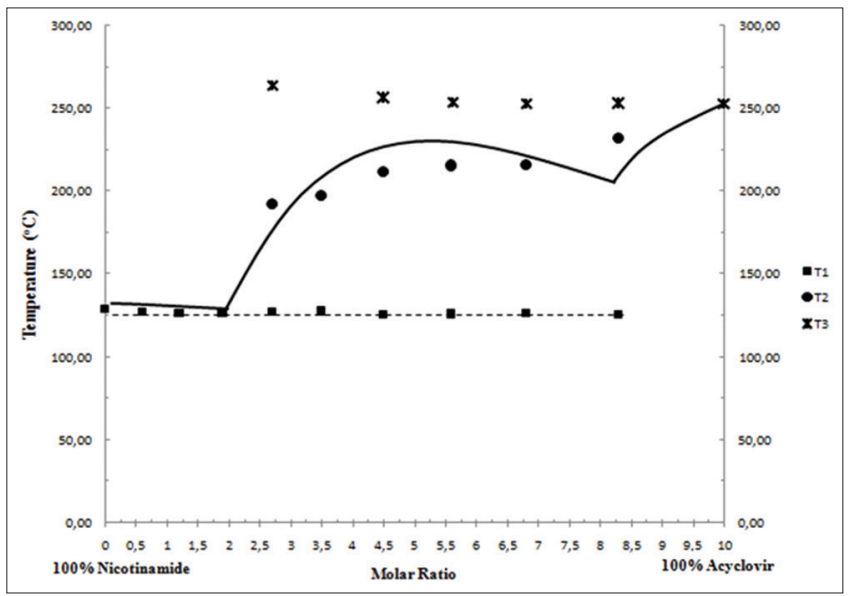

Fig. 1: Phase diagram of binary system acyclovir:nicotinamide (ACV:NCT) with various compositions, T1: Meltingpoint of NCT, T2: Melting point of cocrystal, T3: Melting point of ACV 


\section{Characterization study}

Based on phase diagram data, the ACV-NCT cocrystal used molar ratio of 5:5 or $1: 1$. ACV-NCT cocrystal and their physical mixture were then characterized using DSC as shown in Fig. 2. The result showed ACVNCT cocrystal in ethanol has a new endothermic peak at $221.16^{\circ} \mathrm{C}$ and $\Delta \mathrm{H}=-68.41 \mathrm{~J} / \mathrm{g}$. While the ACV-NCT cocrystal in glacial acetic acid has a new endothermic peak at $216.4016^{\circ} \mathrm{C}$ and $\Delta \mathrm{H}=-64.29 \mathrm{~J} / \mathrm{g}$. These melting point is different with constituent materials ACV and NCT. Hence, this is indicate that ACV-NCT cocrystal with ethanol and glacial acetic acid was successfully formed [17]. Whereas, no peaks were found for $\mathrm{HCl} 0.1 \mathrm{~N}$.

The formation of co-crystals is primarily characterized by PXRD. If the resulting PXRD pattern of the solid product is different from the reactants, it can be concluded that the new solid phase was formed [18]. Fig. 3 shows the PXRD diffractogram of ACV, NCT, ACV-NCT physical mixture, and ACV-NCT cocrystal. ACV has aspecific diffractogram at $2 \theta=6.9^{\circ} ; 10.4^{\circ} ; 16.0^{\circ} ; 20.9^{\circ} ; 26.1^{\circ}$; and $29.2^{\circ}$. NCT has a specific diffractogram at $2 \theta=14.7^{\circ} ; 22.1^{\circ} ; 25.8^{\circ}$; and $27.3^{\circ}$. Diffractogram of ACV-NCT cocrystal in ethanol exhibited new diffraction peaks at $2 \theta 5.9^{\circ} ; 9.2^{\circ}$; dan $13.3^{\circ}$, whereas no peaks were found for glacial acetic acid and $\mathrm{HCl} 0.1 \mathrm{~N}$. Diffractogram of the physical mixture was a superposition of two constituent materials. It is widely accepted that PXRD is a very reliable method to provide information of solid systems in terms of interaction between materials. Such interactions may produce new diffraction peaks as compared to the constituent materials $[1,2,17]$.

FT-IR spectroscopy is widely used to study the chemical and physical structure changes in the molecular structure of substance. The FT-IR spectrum of cocrystal showed relevant changes in the absorption frequencies of the typical functional groups of the pure

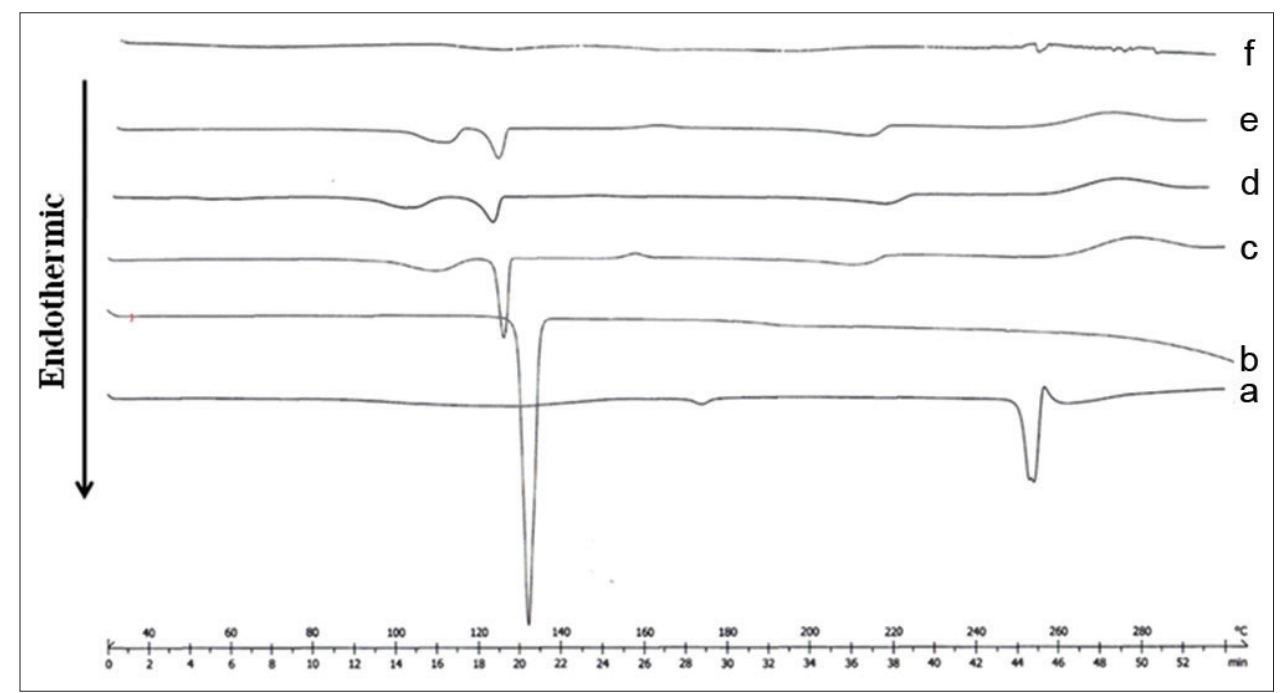

Fig. 2: Differential scanning calorimetry thermogram, (a) acyclovir (ACV), (b) nicotinamide (NCT), (c) ACV-NCT physical mixture, (d) ACV-NCT cocrystal with ethanol, (e) ACV-NCT cocrystal with glacial acetic acid, (f) ACV-NCT cocrystal with HCl $0.1 \mathrm{~N}$

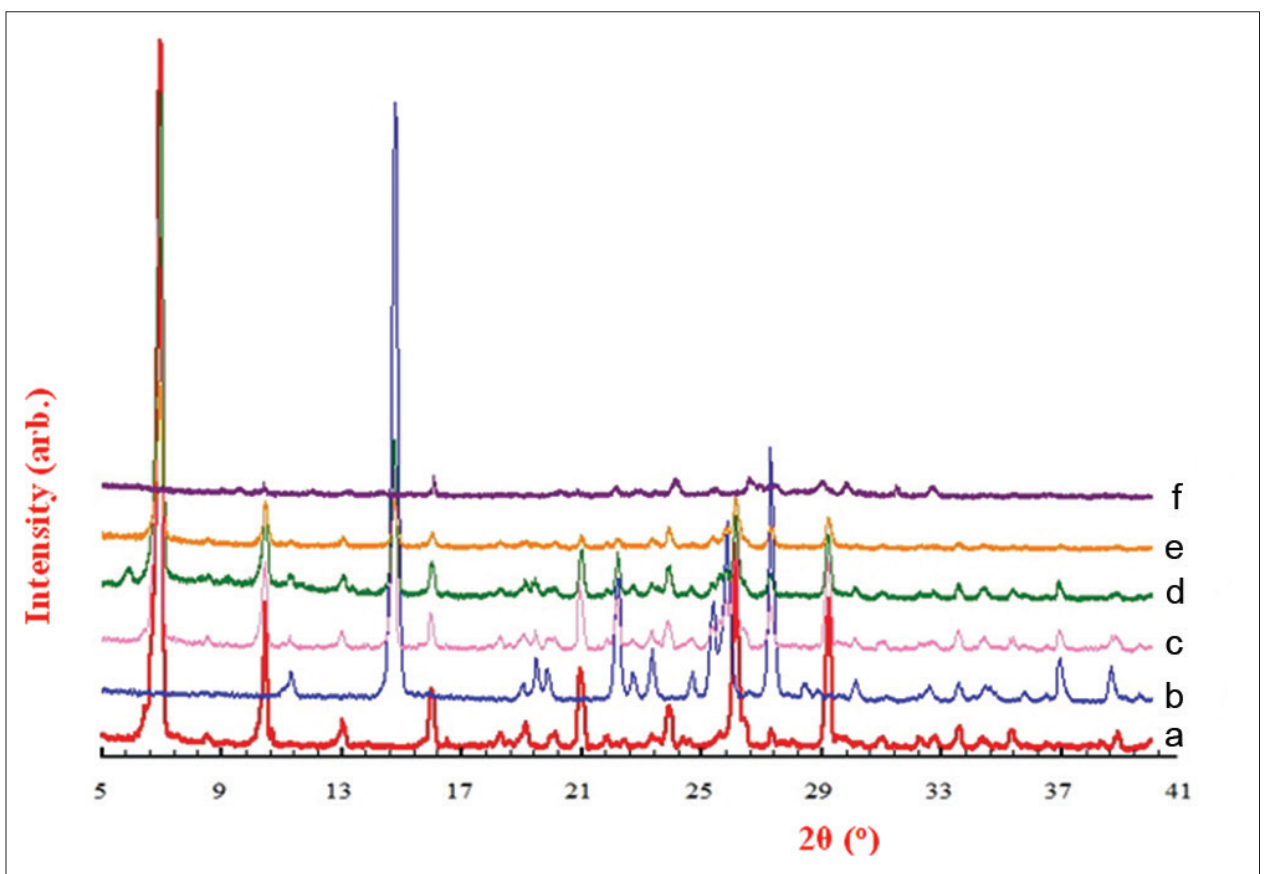

Fig. 3: Powder X-ray diffractogram, (a) acyclovir (ACV), (b) nicotinamide (NCT), (c) ACV-NCT physical mixture, (d) ACV-NCT cocrystal with ethanol, (e) ACV-NCT cocrystal with glacial acetic acid, (f) ACV-NCT cocrystal with HCl $0.1 \mathrm{~N}$ 
substances [1]. Fig. 4 shows that ACV-NCT cocrystal in ethanol showed the disappearance of transmission peaks at $3373 / \mathrm{cm}$ indicating a loss of NH bands of NCT. Furthermore, NH of ACV were observed at $3436 / \mathrm{cm}$, the decrease in the $\mathrm{NH}$ stretching frequency from $3440 / \mathrm{cm} \mathrm{ACV}$ to $3436 / \mathrm{cm}$ in cocrystals implies that primary amine group is participating in hydrogen bond. While $\mathrm{C}=\mathrm{O}$ of $\mathrm{ACV}$ and NCT were observed at $1693 / \mathrm{cm}$ and $1666 / \mathrm{cm}$ indicated a formation of hydrogen bonding between ACV and NCT. ACV-NCT cocrystal in glacial acetic acid showed the mixture of ACV and NCT separately at $3441 / \mathrm{cm}$ and $3374 / \mathrm{cm}$. This suggests that ACV and NCT molecules in glacial acetic acid are not present in the new phase. ACV-NCT cocrystal in $\mathrm{HCl} 0.1 \mathrm{~N}$ showed the $\mathrm{OH}$ bending and stretching frequency were observed at $1660 / \mathrm{cm}$ and $3151 / \mathrm{cm}$. It is suspected that hydrogen bonding interaction with water molecules [19]. This suggested that the formation of ACV-NCT cocrystal in ethanol produced more

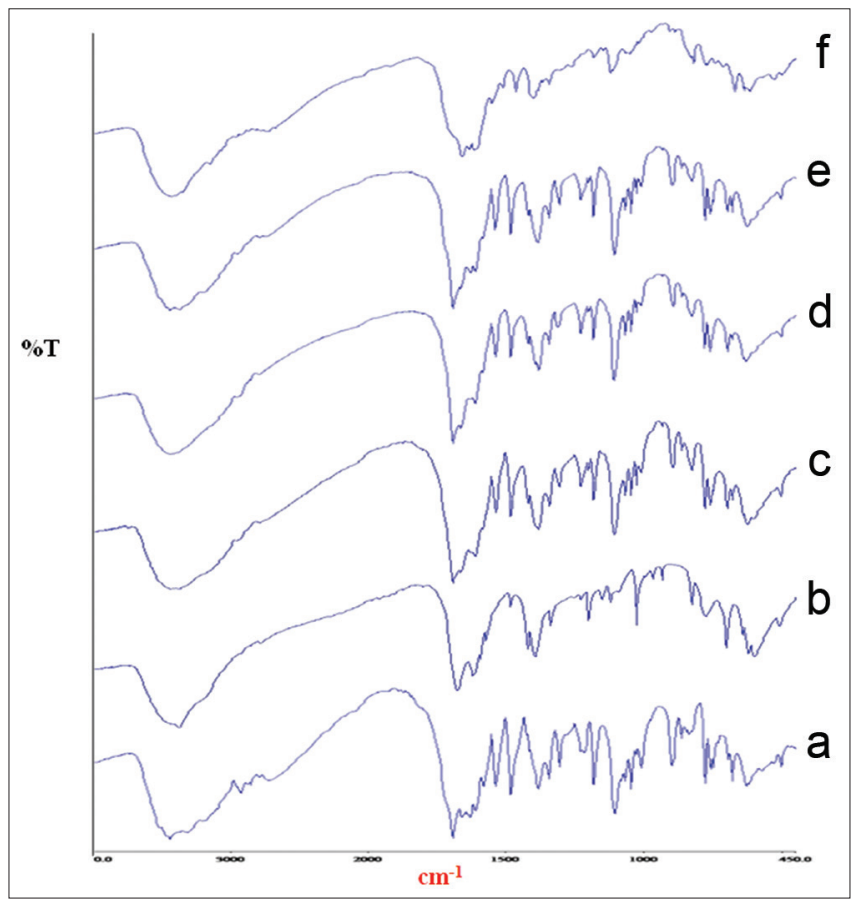

Fig. 4: Infrared spectra, (a) acyclovir (ACV), (b) nicotinamide (NCT), (c) ACV-NCT physical mixture, (d) ACV-NCT cocrystal with ethanol, (e) ACV-NCT cocrystal with glacial acetic acid, (f) ACV-NCT cocrystal with HCl $0.1 \mathrm{~N}$ hydrogen bonding than the ACV-NCT cocrystal in glacial acetic acid and $\mathrm{HCl} 0.1 \mathrm{~N}$

Observations using SEM provide visual information about the differences of cocrystal morphology compared with the constituent materials [1]. The results showed that the ACV-NCT cocrystal in ethanol (Fig. 5c) are made of aggregates of rod shape particles with regular shape and size in which the original morphology of both components (Fig. 5a and b) has disappeared. This indicate that ACV-NCT cocrystal was successfully formed. While ACV-NCT cocystal in glacial acetic acid (Fig. 5d) are made of aggregates and appears of ACV crystal (Fig. 5a) and in $\mathrm{HCl}, 0.1 \mathrm{~N}$ (Fig. 5e) are look like needle shape with irregular size.

\section{Analysis of in vitro dissolution}

Fig. 6 shows that the dissolution tests performed on the samples in powder, in phosphat buffer $\mathrm{pH} 6.8$ at $37^{\circ} \mathrm{C}$. It is evident that dissolution rate at 5 minutes of ACV is very slow, just about $51.00 \pm 2.60$ (Fig. 6a), whereas ACV-NCT cocrystal in ethanol dissolve quite rapidly in about $90.93 \pm 2.48$ (Fig. 6c). While, ACV-NCT physical mixture dissolve in about $72.50+4.26$ (Fig. 6b). ACV-NCT cocrystal in glacial acetic acid dissolve in about $61.13 \% \pm 5.09$ (Fig. 6d). ACV-NCT cocrystal in HCl $0.1 \mathrm{~N}$ dissolve in about 58.92 \pm 1.34 (Fig. 6e) and to be stagnan at 10 minutes until 45 minutes in about $63-66 \%$. This indicates that $\mathrm{HCl}$ cannot increase the dissolution rate of ACV.

The statistic analysis of dissolution efficiency at 15 minutes $\left(\mathrm{DE}_{15}\right)$ with Post-hoc LSD test $(\alpha=0.05)$ showed that there was a significant increase of ACV-NCT cocrystal dissolution rate in ethanol (79.32 \pm 3.04$)$ compared to ACV-NCT physical mixture and ACV. While, ACV-NCT cocrystal in glacial acetic acid has similarity dissolution rate to ACV-NCT physical mixture. Whereas, ACV-NCT cocrystal in $\mathrm{HCl} 0.1 \mathrm{~N}$ did not provide an increase the dissolution rate compared to ethanol and glacial acetic acid.

\section{CONCLUSION}

ACV-NCT cocrystal was successfully formed using solvent evaporation technique with ethanol as solvent. While cocrystallization of ACV and NCT in glacial acetic acid only produces the eutectic mixture. Moreover, ACV-NCT cocrystal in $\mathrm{HCl} 0.1 \mathrm{~N}$ was not successfully formed. This can be proved through their characterization using DSC, PXRD, FT-IR, and SEM. The formed ACV-NCT cocrystal in ethanol exhibits different physicochemical characteristics compared to the constituent materials.

Analysis of $\mathrm{DE}_{15}(\alpha=0.05)$ showed that there was a significant increase of ACV-NCT cocrystal dissolution rate in ethanol compared to ACV-NCT cocrystal in glacial acetic acid and $\mathrm{HCl} 0.1 \mathrm{~N}$.

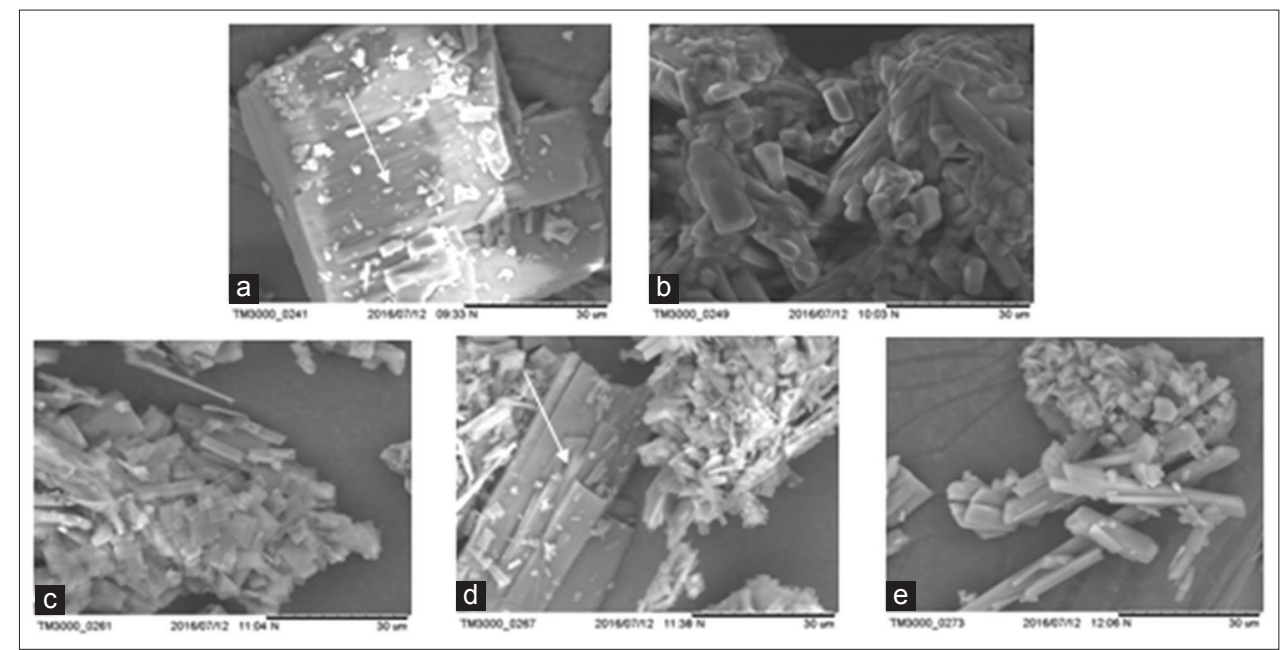

Fig. 5: Scanning electron microscope (a) acyclovir (ACV), (b) nicotinamide (NCT), (c) ACV-NCT physical mixture, (d) ACV-NCT cocrystal with ethanol, (e) ACV-NCT cocrystal with glacial acetic acid, (f) ACV-NCT cocrystal with $\mathrm{HCl} 0.1 \mathrm{~N}$ with a magnification of $\times 2000$ 


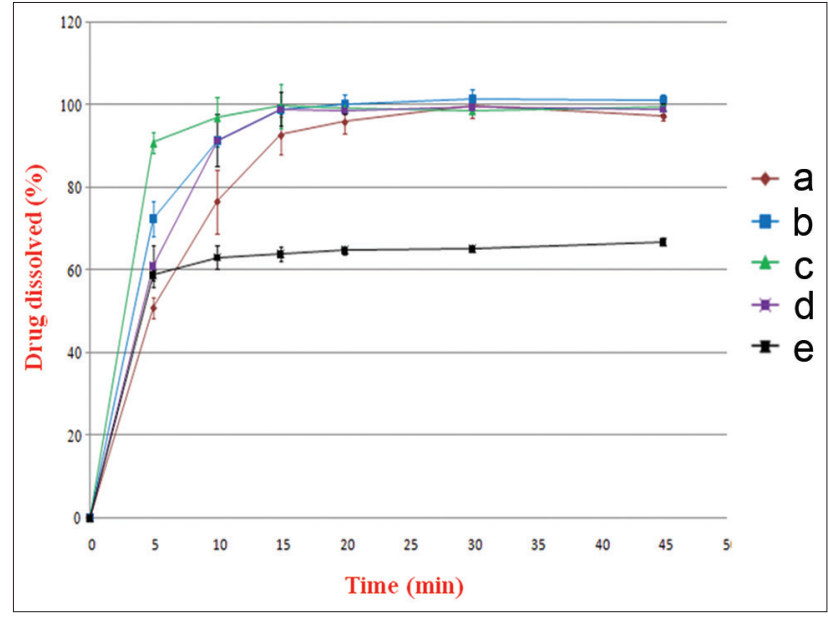

Fig. 6: Dissolution profiles (a) acyclovir (ACV), (b) ACV-NCT physical mixture, (c) ACV-NCT cocrystal with ethanol, (d) ACV-NCT cocrystal with glacial acetic acid, (e) ACV-NCT cocrystal with $\mathrm{HCl}$ $0.1 \mathrm{~N}$. The data obtained is the average of the dissolution rate $\times 3$ replication \pm standsrd deviation

\section{REFERENCES}

1. Bruni G, Maietta M, Maggi L, Mustarelli P, Ferrara C, Berbenni V, et al. Preparation and physicochemical characterization of acyclovir cocrystals with improved dissolution properties. J Pharm Sci 2013;102(11):4079-86

2. Sarkar A, Rohani S. Cocrystals of acyclovir with promising physicochemical properties. J Pharm Sci 2015;104(1):98-105.

3. Yan Y, Chen JM, Lu TB. Simultaneously enhancing the solubility and permeability of acyclovir by crystal engineering approach. CrystEngComm 2013;15:6457-60.

4. Zaini E, Halim A, Soewandhi SN, Setyawan D. Peningkatan laju pelarutan trimetoprim melalui metode ko-kristalisasi dengan nikotinamida. J Farmasi Indones 2011;5(4):205-12.

5. Yadav S, Gupta PC, Sharma N, Kumar J. Cocrystals: An alternative approach to modify physicochemical properties of drugs. Int J Pharm
Chem Biol Sci 2015;5(2):427-36

6. Zalte AG, Saudagar RB. Advanced techniques in preparation of cocrystals. Int J Sci Prog Res 2015;12(1):32-5.

7. Kotak U, Prajapati V, Solanki H, Jani G, Jha P. Co-crystallization technique its rationale and recent progress. World J Pharm Pharm Sci 2015;4(4):1484-508.

8. Fukte SR, Wagh MP, Rawat S. Coformer selection: An important tool in cocrystal formation. Int J Pharm Pharm Sci 2014;6(7):9-14.

9. Setyawan D, Sari R, Yusuf H, Primaharinastiti R. Preparation and characterization of artesunate-nicotinamide cocrystal by solvent evaporation and slurry method. Asian J Pharm Clin Res 2014;7 Suppl 1:62-5.

10. Soares FL, Carneiro RL. Green synthesis of ibuprofen-nicotinamide cocrystals and in-line evaluation by Raman spectroscopy. Cryst Growth Des 2013;13(4):1510-7.

11. Shayanfar A, Velaga S, Jouyban A. Solubility of carbamazepine, nicotinamide, and carbamazepine-nicotinamide cocrystal in ethanolwater mixtures. Fluid Phase Equilib 2014;363:97-105.

12. Rager T, Hilfiker R. Application of phase diagrams in co-crystal search and preparation. In: Johan W, Luc Q, editors. Pharmaceutical Salts and Co-Crystals. $1^{\text {st }}$ ed. Cambridge: The Royal Society of Chemistry; 2012. p. $110-27$.

13. Holan J, Stepánek F, Billot P, Ridvan L. The construction, prediction and measurement of co-crystal ternary phase diagrams as a tool for solvent selection. Eur J Pharm Sci 2014;63:124-31.

14. Grodowska K, Parczewski A. Organic solvents in the pharmaceutical industry. Acta Pol Pharm 2010;67(1):3-12.

15. The United States Pharmacopoeial Convention, Inc. USP 30 NF 25. Vol. 1. Twinbrook Parkway: The United States Pharmacopoeial Convention, Inc.; 2007.

16. Yamashita H, Hirakura Y, Yuda M, Teramura T, Terada K. Detection of cocrystal formation based on binary phase diagrams using thermal analysis. Pharm Res 2012;30(1):1-11

17. Masuda T, Yoshihashi Y, Yonemochi E, Fujii K, Uekusa H, Terada K. Cocrystallization and amorphization induced by drug-excipient interaction improves the physical properties of acyclovir. Int J Pharm 2012;422(1-2):160-9.

18. Alatas F, Soewandhi SN, Sasongko L, Ismunandar, Uekusa H. Cocrystal formation between didanosine and two aromatic acids. Int J Pharm Pharm Sci 2013;5 Suppl 3:275-80.

19. Gerakines PA, Schutte WA, Greenberg JM, van Dishoeck EF. The infrared band strengths of $\mathrm{H} 2 \mathrm{O}, \mathrm{CO}$, and $\mathrm{CO} 2$ in laboratory simulaions of astrophysical ice mixtures. Astron Astrophys 1995;296:1-17. 